\title{
Meat, vegetables and genetic polymorphisms and the risk of colorectal carcinomas and adenomas
}

\author{
Camilla F Skjelbred ${ }^{\dagger 1,2}$, Mona Sæbø ${ }^{\dagger 2}$, Anette Hjartåker ${ }^{3}$, Tom Grotmol 3 , \\ Inger-Lise Hansteen ${ }^{1,2}$, Kjell M Tveit ${ }^{4}$, Geir Hoff ${ }^{3}$ and Elin H Kure*2,4,5
}

\begin{abstract}
Address: ${ }^{1}$ Department of Laboratory Medicine, Section of Medical Genetics, Telemark Hospital, N-3710 Skien, Norway, ${ }^{2}$ Telemark University College, Faculty of Arts and Sciences, Department of Environmental and Health Studies, Hallvard Eikas plass, N-3800 Bø i Telemark, Norway, ${ }^{3}$ The Cancer Registry of Norway, Institute of Population-based Cancer Research, N-0310 Oslo, Norway, ${ }^{4}$ The Cancer Center, Ulleval University Hospital, 0407 Oslo, Norway and ${ }^{5}$ Department of Pathology, Ulleval University Hospital, 0407 Oslo, Norway

Email: Camilla F Skjelbred - camilla-furu.skjelbred@sthf.no; Mona Sæbø - mona.sabo@ hit.no; Anette Hjartåker - anette.hjartaker@kreftregisteret.no; Tom Grotmol - tom.grotmol@kreftregisteret.no; Inger-Lise Hansteen - ingerlise.hansteen@sthf.no; Kjell M Tveit - kjell.tveit@uus.no; Geir Hoff - hofg@online.no; Elin H Kure* - elin.kure@hit.no

* Corresponding author †Equal contributors
\end{abstract}

Published: 19 December 2007

BMC Cancer 2007, 7:228 doi:10.1 |86/147|-2407-7-228
Received: 14 December 2006

Accepted: 19 December 2007

This article is available from: http://www.biomedcentral.com//47/-2407/7/228

(C) 2007 Skjelbred et al; licensee BioMed Central Ltd.

This is an Open Access article distributed under the terms of the Creative Commons Attribution License (http://creativecommons.org/licenses/by/2.0), which permits unrestricted use, distribution, and reproduction in any medium, provided the original work is properly cited.

\begin{abstract}
Background: The risk of sporadic colorectal cancer (CRC) is mainly associated with lifestyle factors, particularly dietary factors. Diets high in red meat and fat and low in fruit and vegetables are associated with an increased risk of CRC. The dietary effects may be modulated by genetic polymorphisms in biotransformation genes. In this study we aimed to evaluate the role of dietary factors in combination with genetic factors in the different stages of colorectal carcinogenesis in a Norwegian population.
\end{abstract}

Methods: We used a case-control study design (234 carcinomas, 229 high-risk adenomas, 762 low-risk adenomas and 400 controls) to test the association between dietary factors (meat versus fruit, berries and vegetables) genetic polymorphisms in biotransformation genes (GSTMI, GSTTI, GSTPI Ile ${ }^{105} \mathrm{Val}$, EPHXI Tyr ${ }^{13} \mathrm{His}$ and EPHXI His ${ }^{139} \mathrm{Arg}$ ), and risk of colorectal carcinomas and adenomas. Odds ratio (OR) and $95 \%$ confidence interval $(95 \% \mathrm{Cl})$ were estimated by binary logistic regression.

Results: A higher ratio of total meat to total fruit, berry and vegetable intake was positively associated with both high and low-risk adenomas, with approximately twice the higher risk in the $2^{\text {nd }}$ quartile compared to the lowest quartile. For the high-risk adenomas this positive association was more obvious for the common allele (Tyr allele) of the EPHXI codon II 3 polymorphism. An association was also observed for the EPHXI codon II 3 polymorphism in the low-risk adenomas, although not as obvious.

Conclusion: Although, the majority of the comparison groups are not significant, our results suggest an increased risk of colorectal adenomas in individuals for some of the higher ratios of total meat to total fruit, berry and vegetable intake. In addition the study supports the notion that the biotransformation enzymes GSTMI, GSTPI and EPHXI may modify the effect of dietary factors on the risk of developing colorectal carcinoma and adenoma. 


\section{Background}

Colorectal cancer (CRC) is one of the most prevalent diseases in the industrialized Western countries. In Norway, with one of the highest incidence rates in the world, approximately 3500 new cases of CRC are diagnosed every year [1].

Epidemiological studies have attributed more than $85 \%$ of CRCs to environmental factors [2,3], particularly dietary factors [4]. Diets high in red meat and fat and low in fruit and vegetables are associated with an increased risk of CRC $[5,6]$. Although not entirely consistent, results from case-control and cohort studies suggest a modest association between intake of red meat and risk of CRC [7-9]. The mechanism behind the specific risk-enhancing effect of red meat is not precisely known, but there is evidence suggesting that components of red meat may independently increase the risk of CRC [10]. It has also been suggested that any association between high meat consumption and CRC may be a result of deficiencies in other protective dietary factors, such as fruit and vegetables $[11,12]$. In contrast to earlier studies, more recent epidemiological studies have generally not supported a strong influence of dietary fiber or fruit and vegetables, although these have other health benefits [10]. This has led to the notion that it is the ratio between meat and fruit/vegetable intake that is important. A study by Kapiszewska [13] showed that both the ratio between vegetables and meat consumption, as well as the ratio between the amount of energy from vegetables and animal products, can be used successfully to evaluate the relation of dietary pattern to cancer risk.

It is widely known that humans differ in their susceptibility to cancer. Difference in carcinogen metabolism might explain the differences in cancer susceptibility especially as most cancers are influenced by environmental factors [14]. Dietary effects might be modulated by genetic polymorphisms in biotransformation genes [15]. In the biotransformation system there are several interesting genes including microsomal epoxide hydrolase (EPHX1) (phase I) and gluthatione S-transferases (GSTs) (phase II), all with known polymorphisms [16,17].

The EPHX1 gene has a dual function and catalyzes the hydrolysis of arene, alkene and aliphatic epoxides to less reactive and more water-soluble dihydrodiols, but activates some polycyclic aromatic hydrocarbons into a more carcinogenic form [18]. A tyrosine to histidine substitution in exon 3 ( $\mathrm{Tyr}^{113} \mathrm{His}$ ) of the EPHX1 gene decreases in vitro enzyme activity by $40 \%$, whereas a histidine to arginine substitution in exon 4 (His ${ }^{139} \mathrm{Arg}$ ) increases in vitro enzyme activity by $25 \%$ [19].
GSTs are responsible for the glutathione conjugation and detoxify a number of various reactive species [20]. Genetic polymorphisms that result in reduced or absent activity or expression of the GST enzyme are known for most GST isoforms [21]. Research has mostly focused on the GSTM1 and GSTT1 deletion polymorphisms ("null" genotypes) resulting in absence of the GST $\mu 1$ and GST $\mu$ l enzymes [22], and the GSTP1 Ile ${ }^{105}$ Val polymorphism resulting in a less active enzyme [23].

Several lines of evidence support the adenoma - carcinoma sequence as the major path for colorectal carcinogenesis. The present study aimed to investigate the role of dietary factors (meat and fruit/vegetables) in combination with genetic factors in the different stages of colorectal carcinogenesis in a Norwegian population.

\section{Methods}

The KAM cohort (Kolorektal cancer, Arv og Miljø) is based on the screening group of the Norwegian Colorectal Cancer Prevention study (The NORCCAP study) in the county of Telemark [24], and a series of clinical CRC cases (mean age 67.3, SD 11.2) operated on at Telemark Hospital (Skien) and Ulleval University Hospital (Oslo). Those invited to participate in the NORCCAP study were 20,780 men and women, age 50-64 years old, drawn by randomization from the population registry in Oslo (urban) and the county of Telemark (mixed urban and rural). They were invited to have a flexible sigmoidoscopy screening examination with or without $(1: 1)$ an additional faecal occult blood test (FOBT). Seven hundred and seventyseven individuals were excluded according to exclusion criteria. The overall attendance rate was $65 \%$. The ID number for the NORCCAP study at ClinicalTrials.gov is I NCT00119912 [25]. The screened cases in the NORCCAP study selected for colonoscopy were invited to participate in the KAM study (1044 cases agreed). During a limited period of time, after the screening study of NORCCAP was well established, controls (polyp free by flexible sigmoidoscopy) were invited to participate in the KAM study (400 controls agreed). The KAM cohort is based on an ethnic homogenous group of Norwegian origin. Written consent was obtained from all the participants. The KAM study is approved by the Regional Ethics Committee and the Data Inspectorate.

The KAM biobank consists of blood and tissue samples from 234 CRC cases (16 identified in the NORCCAP screening group and 218 from hospitals), 1044 individuals identified with polyps in the large intestine (229 highrisk and 762 low-risk adenomas, 53 hyperplastic polyps) and 400 controls, defined as individuals with normal findings at flexible sigmoidoscopy screening. Adenoma cases and controls were all drawn from the NORCCAP study. All of the participants completed a questionnaire 
on demographics, health status, dietary and smoking habits, alcohol consumption, physical exercise and occupation. The questionnaire contained information on a family history of adenomas and carcinomas, and the cases and controls included had no known personal history of genetic predisposition.

Diet was assessed in cases and controls using an extensive diet and lifestyle questionnaire, modeled on a questionnaire developed and validated for an American breast cancer study [26-28]. It was designed in a food frequency manner, asking the participants to record their average consumption, during the last year, of a wide range of typically Norwegian food items by ticking off fixed frequency and portion size boxes. Nine frequency choices, ranging from "never/less than once per month" to " 2 or more per day" were given, whereas portion size was recorded as small, medium or large. The medium portion size was defined in the questionnaire (e.g. units, grams, dl). A small portion was defined as half or less than half of the medium portion, and a large portion was defined as one and a half or more of the medium portion. All questionnaires were checked for mistakes and completeness, and the participants who had delivered an inadequate questionnaire were contacted by phone in order to improve the quality of the data.

The adenocarcinomas were collected prior to chemo- or radiotherapy treatment. Two specialists in histopathology examined the histology of the adenomas independently in order to determine the tumor stage as mild, moderate or severe dysplasia. They reached the same conclusion in all cases.

Diminished numbers of available cases in the KAM biobank and analyzed cases are due to loss of samples during preparation and/or lack of information from the questionnaires. The 53 hyperplastic polyps were not included in the present analysis. A high-risk adenoma was defined as an adenoma measuring $=10 \mathrm{~mm}$ in diameter and/or with villous components and/or showing severe dysplasia [24].

Genomic DNA was isolated from blood samples according to standard procedures [29] with minor modifications as previously described [30].

Polymorphisms of the GSTM1 (null), GSTT1 (null) and GSTP1 (Ile $\left.{ }^{105} \mathrm{Val}\right)$ genes were analyzed simultaneously by multiplex PCR as described by Nedelcheva Kristensen et al.[31].

The EPHX1 His ${ }^{139}$ Arg polymorphism (rs2234922) was analyzed by a PCR-RFLP (restriction fragment length polymorphism) method as described by Hasset et al.[19].
Genotype analysis of the EPHX1 Tyr ${ }^{113}$ His polymorphism (rs1051740) was carried out using the TaqMan allelic discrimination assay on a Sequence Detection System ABI 7000 (Applied Biosystems), using the primers forward: 5'TCT CCT ACT GGC GGA ATG AAT T-3', reverse: 5'-CTG GCT GGC GTT TTG CA-3' and the probes T-allele: 5'-VICTCT CAA CAG ATA CCC TCA-MGB-3', C-allele: 5'-6-FAMTCA ACA GAC ACC CTC A-MGB-3'. The polymorphism was determined in a $12 \mu \mathrm{l}$ reaction containing $1 \times$ MasterMix, $200 \mathrm{nM}$ of each probe, $900 \mathrm{nM}$ primers, and ca $50 \mathrm{ng}$ of genomic DNA. Cycling conditions were as follows: $50{ }^{\circ} \mathrm{C}$ for $2 \mathrm{~min}, 95^{\circ} \mathrm{C}$ for $10 \mathrm{~min}$, and 45 cycles of $95^{\circ} \mathrm{C}$ for $15 \mathrm{~s}$ and $60^{\circ} \mathrm{C}$ for $1 \mathrm{~min}$. Controls were included in each run, and $10 \%$ of the samples were retyped with identical results.

Eight summary variables were created from the individual dietary items in the food frequency questionnaire to describe the intake of red meat, processed meat, total meat, raw vegetables, boiled vegetables, fruit and berries, total fruit, berries and vegetables and the ratio between total meat and fruit, berry and vegetable intake. For each individual dietary factor, the frequency and portion size were multiplied to obtain the amount in grams per day. The summary variables were then divided into quartiles based on distribution of consumption among controls.

Differences in characteristics between the control group and all the case groups were assessed using the $\chi^{2}$ test for categorical variables and the Mann-Whitney test for continuous variables. P-values $<0.05$ were considered significant. Odds ratios (ORs) and 95\% confidence intervals (CI) were calculated using binary logistic regression analysis to assess the relationship between the dietary factors, each polymorphism and colorectal carcinoma or adenoma cases. Crude ORs were calculated, adjusted for age and gender only. In addition multiple logistic regression analyses were performed with an adjustment for age, gender, smoking dose, alcohol consumption, and when appropriate total meat consumption and total fruit, berry and vegetable consumption. In addition the modifying effect by genotype on dietary exposure (ratio of total meat to total fruit, berry and vegetable intake) was studied by stratification in a two by four table. All analyses were carried out using the statistical analysis software SPSS (Chicago, Illinois, USA) 12.0.1 for Windows.

\section{Results}

Selected characteristics of cases and controls are shown in Table 1 . The gender distribution was dissimilar in the control and the case groups. Cases were older and more often smokers. The low-risk adenoma cases had a higher alcohol intake than the controls. Low-risk adenoma cases had a higher total meat intake than controls, and the high and 
Table I: Distribution of age, gender, cigarette smoking, alcohol consumption and dietary factors among controls and cases with colorectal carcinomas and adenomas

\begin{tabular}{|c|c|c|c|c|}
\hline & Controls & Carcinomas & High-risk adenomas & Low-risk adenomas \\
\hline No. of subjects & 400 & 234 & 229 & 762 \\
\hline \multicolumn{5}{|l|}{ Gendera } \\
\hline Male, No (\%) & $157(39.3)$ & $128(54.7)$ & I5I (65.9) & $456(59.8)$ \\
\hline Female, No (\%) & $243(60.8)$ & $106(45.3)$ & $78(34.1)$ & $306(40.2)$ \\
\hline \multicolumn{5}{|l|}{$\mathbf{A g e}^{\mathrm{b}}$} \\
\hline Mean, years (SD) & $54.2(3.3)$ & $67.3(11.2)$ & $57.3(3.5)$ & $57.3(3.8)$ \\
\hline \multicolumn{5}{|l|}{ Smoking status } \\
\hline Never smoked, No (\%) & $156(46.7)$ & $67(38.5)$ & $52(27.1)$ & $206(31.5)$ \\
\hline Ever smoked, No (\%) & $178(53.3)$ & $107(61.5)$ & $140(72.9)$ & $448(68.5)$ \\
\hline Number of cigarette yearsc, median (25-75 percentile) & $213(58.8-362.0)$ & $300(120.0-546.0)$ & $350(210.3-484.8)$ & $314(137.0-468.0)$ \\
\hline \multicolumn{5}{|l|}{ Alcohol consumption } \\
\hline Never, No (\%) & $73(21.8)$ & $43(25.3)$ & $45(22.6)$ & $147(21.9)$ \\
\hline Ever, No (\%) & $262(78.2)$ & $127(74.7)$ & $154(77.4)$ & $523(78.1)$ \\
\hline Number of alcohol units per month ${ }^{d}$, median ( $25-75$ percentile) & $6.5(2.5-16.0)$ & $10.5(4.0-25.0)$ & $9.0(5.0-20.1)$ & $9.0(4.5-19.0)$ \\
\hline \multicolumn{5}{|l|}{ Dietary intake in g/day, median (25-75 percentile) } \\
\hline Red meat consumption & $25(16.5-45.0)$ & $24(12.0-39.4)$ & $27(16.5-45.0)$ & $27(16.5-45.0)$ \\
\hline Processed meat consumptione & $70(40.2-112.9)$ & $62(31.6-95.2)$ & $77(42.1-120.9)$ & $77(46.1-113.6)$ \\
\hline Total meat consumption $f$ & $99(63.5-154.5)$ & $90(53.4-134.5)$ & $112(71.0-163.0)$ & $112(74.9-154.9)$ \\
\hline Raw vegetable consumption & $52(22.8-84.8)$ & $41(19.2-81.0)$ & $42(19.9-75.0)$ & $45(22.9-80.1)$ \\
\hline Boiled vegetable consumptiong & 58 (34.9-94.7) & $74(39.2-108.1)$ & $64(38.7-100.3)$ & $67(40.2-108.3)$ \\
\hline Fruit and berry consumption ${ }^{h}$ & $14 \mid(74.1-224.3)$ & $106(51.9-190.1)$ & $122(54.7-200.5)$ & $118(59.7-199.6)$ \\
\hline Total fruit, berry and vegetable consumption & $265(166.4-390.9)$ & $250(149.7-378.4)$ & $230(156.2-372.1)$ & $24 \mid(157.6-358.7)$ \\
\hline Ratio of total meat to total fruit, berry and vegetable intake ${ }^{i}$ & $0.38(0.19-0.71)$ & $0.40(0.20-0.63)$ & $0.43(0.26-0.76)$ & $0.45(0.27-0.82)$ \\
\hline
\end{tabular}

a There are significant differences in the number of males and females between the control group and all the case groups, $\mathrm{P}<\mathrm{I0}-4$.

$\mathrm{b}$ There are significant differences in age between the control group and all the case groups, $\mathrm{P}<10^{-4}$.

c There are significant differences in number of cigarette years (smoking dose) between the control group and all of the case groups, $\mathrm{P}=0.00 \mathrm{I}, \mathrm{P}<$

$10^{-4}$ and $\mathrm{P}<10^{-4}$, respectively.

$\mathrm{d}$ There is significant difference in number of alcohol units per month between the control group and the low-risk adenoma group, $\mathrm{P}=0.0 \mathrm{I} 3$.

e There is significant difference in processed meat consumption ( $g /$ day) between the control group and the low-risk adenoma group, $\mathrm{P}=0.04 \mathrm{I}$.

$\mathrm{f}$ There is significant difference in total meat consumption $(\mathrm{g} / \mathrm{day})$ between the control group and the low-risk adenoma group, $\mathrm{P}=0.027$.

$\mathrm{g}$ There is significant difference in boiled vegetable consumption $(\mathrm{g} / \mathrm{day})$ between the control group and the low-risk adenoma group, $\mathrm{P}=0.035$.

$\mathrm{h}$ There are significant differences in fruit and berry consumption ( $g /$ day) between the control group and the carcinoma and low-risk adenoma groups, $\mathrm{P}=0.019$ and $\mathrm{P}=0.005$, respectively.

i There are significant differences in ratio of total meat to total fruit, berry and vegetable intake between the control group and the high- and lowrisk adenoma groups, $P=0.035$ and $P=0.003$, respectively.

Missing values for cigarette smoking, alcohol consumption and dietary factors gave rise to diminished number of cases and controls.

low-risk adenoma cases had a higher ratio of intake of total meat to total fruit, berries and vegetables.

The distribution of consumption of the dietary factors in quartiles is presented in Table 2, and the genotype distribution is shown in Table 3. The tables also present the estimates of ORs of colorectal carcinomas and adenomas associated with the various dietary factors and polymorphisms. The tables present only data from the multiadjusted model which may be a better choice than the crude model in reducing potential confounding in the data.

No significant trends were observed in the data of Table 2. Total meat consumption showed a borderline significant association with low-risk adenomas in the $3^{\text {rd }}$ quartile, OR of 1.57 (95\% CI 1.00-2.46). No significant results were observed for total fruit, berry and vegetable consumption. The ratio of total meat to total fruit, berry and vegetable intake was positively associated with both high and lowrisk adenomas in the $2^{\text {nd }}$ quartile (and $3^{\text {rd }}$ quartile for lowrisk adenomas) with approximately twice the higher risk compared to the lowest quartile (ORs of 2.59 (95\% CI $1.31-5.14)$ and 1.73 (95\% CI 1.08-2.75), respectively). We have also tested the dietary exposures as binary variables, but these results gave less information than the chosen model (data not shown).

The frequencies for the GSTM1 null allele, GSTT1 null allele, GSTP1 105Val allele, EPHX1 113His allele and EPHX1 139Arg allele among the controls were respectively, $0.52,0.13,0.37,0.32$ and 0.21 (Table 3 ). The gen- 
Table 2: Association between intake of dietary factors and colorectal carcinomas and adenomas

\begin{tabular}{|c|c|c|c|c|c|c|c|}
\hline & Controls & Carcinomas & OR $(95 \% \mathrm{Cl})^{\mathrm{a}}$ & High-risk adenomas & OR $(95 \% \mathrm{CI})^{\mathrm{a}}$ & Low-risk adenomas & OR $(95 \% \mathrm{Cl})^{\mathrm{a}}$ \\
\hline \multicolumn{8}{|l|}{ Dietary factors $\underline{b}$} \\
\hline \multicolumn{8}{|l|}{ Total meat } \\
\hline$\leq 64$ & 72 & 37 & I (ref) & 35 & I (ref) & 107 & I (ref) \\
\hline$>64$ and $\leq 99$ & 77 & 29 & $1.00(0.43-2.32)$ & 42 & $1.07(0.56-2.06)$ & 139 & $1.05(0.66-1.67)$ \\
\hline$>99$ and $\leq 155$ & 77 & 33 & $1.88(0.82-4.31)$ & 49 & $1.46(0.76-2.78)$ & 186 & $1.57(1.00-2.46)$ \\
\hline \multirow[t]{2}{*}{$>155$} & 74 & 27 & $0.93(0.38-2.30)$ & 49 & $1.22(0.63-2.37)$ & 149 & $1.06(0.66-1.70)$ \\
\hline & & & $P_{\text {trend }}=0.67$ & & $P_{\text {trend }}=0.4 \mathrm{I}$ & & $P_{\text {trend }}=0.43$ \\
\hline \multicolumn{8}{|c|}{ Total fruit, berry and vegetable } \\
\hline$\leq 166$ & 76 & 36 & I (ref) & 53 & I (ref) & 159 & I (ref) \\
\hline$>166$ and $\leq 265$ & 73 & 35 & $0.82(0.36-1.88)$ & 49 & $1.00(0.55-1.80)$ & 168 & $1.12(0.73-1.74)$ \\
\hline$>265$ and $\leq 391$ & 75 & 27 & $0.83(0.36-1.92)$ & 37 & $0.78(0.4 \mid-1.46)$ & 130 & $1.02(0.65-1.59)$ \\
\hline \multirow[t]{2}{*}{$>391$} & 75 & 28 & $1.52(0.67-3.45)$ & 36 & $1.03(0.55-1.95)$ & 124 & $0.99(0.63-1.57)$ \\
\hline & & & $P_{\text {trend }}=0.37$ & & $P_{\text {trend }}=0.86$ & & $P_{\text {trend }}=0.87$ \\
\hline \multicolumn{8}{|c|}{ Ratio of total meat to total fruit, berry and vegetable intake } \\
\hline$\leq 0.19$ & 75 & 27 & I (ref) & 22 & I (ref) & 90 & I (ref) \\
\hline$>0.19$ and $\leq 0.38$ & 74 & 33 & $1.66(0.72-3.84)$ & 55 & $2.59(1.31-5.14)$ & 146 & $1.73(1.08-2.75)$ \\
\hline$>0.38$ and $\leq 0.7 \mathrm{I}$ & 75 & 45 & $1.58(0.69-3.63)$ & 45 & $1.49(0.73-3.02)$ & 176 & $1.68(1.06-2.67)$ \\
\hline \multirow[t]{2}{*}{$>0.71$} & 75 & 21 & $0.62(0.23-1.62)$ & 53 & $1.92(0.95-3.91)$ & 169 & $1.39(0.85-2.25)$ \\
\hline & & & $P_{\text {trend }}=0.39$ & & $P_{\text {trend }}=0.37$ & & $P_{\text {trend }}=0.29$ \\
\hline
\end{tabular}

a Adjusted for age, gender, smoking dose and alcohol consumption. In addition 'Total meat' and 'Total fruit, berry and vegetable' are mutually adjusted for when assessing their main effect. These variables were not adjusted for when the ratio between them was assessed.

$\mathrm{b}$ Quantities are gram per day. Categories based on quartiles. Numbers vary between the dietary factors due to missing dietary data. ref: served as reference category.

Table 3: Association between GST and EPHXI genotypes and colorectal carcinomas and adenomas

\begin{tabular}{|c|c|c|c|c|c|c|c|}
\hline & Controls & Carcinomas & OR $(95 \% \mathrm{Cl})^{\mathrm{a}}$ & High-risk adenomas & OR $(95 \% \mathrm{Cl})^{a}$ & Low-risk adenomas & OR $(95 \% \mathrm{CI})^{\mathrm{a}}$ \\
\hline \multicolumn{8}{|l|}{ Genotypes $\underline{\underline{b}}$} \\
\hline Present & 148 & 53 & I (ref) & 84 & I (ref) & 262 & I (ref) \\
\hline Null & 151 & 55 & $1.22(0.65-2.30)$ & 89 & $0.98(0.63-1.52)$ & 313 & $1.09(0.80-1.49)$ \\
\hline \multicolumn{8}{|l|}{ GSTTI } \\
\hline Present & 262 & 93 & I (ref) & 143 & I (ref) & 488 & I (ref) \\
\hline Null & 37 & 15 & $1.37(0.57-3.31)$ & 30 & $1.36(0.72-2.55)$ & 87 & $0.99(0.63-1.58)$ \\
\hline \multicolumn{8}{|l|}{ GSTPI Ile ${ }^{05} \mathrm{Val}$} \\
\hline Ile/lle & 119 & 51 & I (ref) & 57 & I (ref) & 240 & I (ref) \\
\hline Ile/Val & 140 & 50 & $0.82(0.43-1.59)$ & 90 & $1.27(0.78-2.06)$ & 272 & $1.00(0.7 \mid-1.39)$ \\
\hline $\mathrm{Val} / \mathrm{Val}$ & 40 & 7 & $0.38(0.12-1.23)$ & 26 & $1.29(0.65-2.59)$ & 63 & $0.79(0.48-1.32)$ \\
\hline \multirow[t]{2}{*}{$\mathrm{lle} / \mathrm{Val}+\mathrm{Val} / \mathrm{Val}$} & 180 & 57 & $0.71(0.38-1.32)$ & 116 & $1.27(0.80-2.02)$ & 335 & $0.95(0.69-1.31)$ \\
\hline & & & $P_{\text {trend }}=0.13$ & & $P_{\text {trend }}=0.35$ & & $P_{\text {trend }}=0.49$ \\
\hline \multicolumn{8}{|l|}{ EPHXI Tyr ${ }^{1 / 3} \mathrm{His}$} \\
\hline Tyr/Tyr & 132 & 52 & I (ref) & 75 & I (ref) & 304 & I (ref) \\
\hline Tyr/His & 134 & 41 & $0.74(0.37-1.47)$ & 81 & $0.90(0.57-1.44)$ & 229 & $\mathbf{0 . 6 9}(0.50-0.97)$ \\
\hline $\mathrm{His} / \mathrm{His}$ & 33 & 9 & $1.04(0.33-3.21)$ & 17 & $0.87(0.40-1.88)$ & 43 & $0.56(0.32-0.99)$ \\
\hline \multirow[t]{2}{*}{$\mathrm{Tyr} / \mathrm{His}+\mathrm{His} / \mathrm{His}$} & 167 & 50 & $0.78(0.4 \mid-1.5 \mathrm{I})$ & 98 & $0.90(0.57-1.40)$ & 272 & $\mathbf{0 . 6 7}(0.49-0.92)$ \\
\hline & & & $P_{\text {trend }}=0.68$ & & $P_{\text {trend }}=0.63$ & & $P_{\text {trend }}=0.01$ \\
\hline \multicolumn{8}{|l|}{ EPHXI His ${ }^{139} \mathrm{Arg}$} \\
\hline $\mathrm{His} / \mathrm{His}$ & 190 & 56 & I (ref) & 106 & I (ref) & 347 & I (ref) \\
\hline His/Arg & 90 & 27 & $1.24(0.60-2.57)$ & 59 & $1.37(0.85-2.21)$ & 207 & $1.24(0.88-1.74)$ \\
\hline Arg/Arg & 19 & 18 & $2.70(0.96-7.58)$ & 8 & $0.62(0.23-1.70)$ & 22 & $0.51(0.25-1.06)$ \\
\hline \multirow[t]{2}{*}{$\mathrm{His} / \mathrm{Arg}+\mathrm{Arg} / \mathrm{Arg}$} & 109 & 45 & $1.52(0.79-2.93)$ & 67 & $1.22(0.77-1.91)$ & 229 & $1.11(0.80-1.53)$ \\
\hline & & & $P_{\text {trend }}=0.09$ & & $P_{\text {trend }}=0.82$ & & $P_{\text {trend }}=0.83$ \\
\hline
\end{tabular}

a Adjusted for age, gender, smoking dose, alcohol consumption, and the consumption of total meat and total fruit, berry and vegetable.

b Numbers vary between analyzed genotypes due to missing samples and/or failed analysis.

ref: the genotype served as reference category. 
otype distributions were all in Hardy-Weinberg equilibrium and the distributions of the alleles are in agreement with those found in other Caucasian populations [32-34]. No significant associations were found between the GST polymorphisms and risk of colorectal carcinomas and adenomas. The EPHX1 113His allele was associated with a decreased risk in low-risk adenomas with OR of 0.67 (95\% CI 0.49-0.92), $P_{\text {trend }}=0.01$. No significant associations were seen between the EPHX1 139Arg allele and carcinomas and adenomas. Since the strongest association seems to be with the Arg/Arg genotype we have compared this genotype with the combined His/His and His/Arg genotypes as a reference. The Arg/Arg genotype was associated with decreased risk of low-risk adenomas only, OR of 0.48 (95\% CI 0.23-0.98) (data not shown). We have also tested the combined effect of the two polymorphisms in EPHX1 (i.e., $\mathrm{Tyr}^{113} \mathrm{His}$ and His ${ }^{139} \mathrm{Arg}$ ). Predicted mEPHX activities were classified as normal, fast and slow [35]. The same tendency was observed as for the separate genotypes (data not shown).

Table 4 display the results from analyses of the effect of the ratio of total meat to total fruit, berry and vegetable intake on the risk of colorectal carcinomas and adenomas stratified by genotype. The case groups are stratified based on polymorphic status, in most common allele or any polymorphic allele. Only data from the multi-adjusted model is presented.

No significant trends were observed. For carcinomas we did not find any significant association with ratio of total meat to total fruit, berry and vegetable intake, and the combination with genotype gives few significant results. A reduced risk $\left(\mathrm{Q}_{4}\right)$ was observed in individuals with the GSTP1 codon 105 variant allele (Val allele). In addition a positive association between ratio $\left(\mathrm{Q}_{2}\right)$ and CRC risk was more obvious in individuals with the EPHX1 codon 139 common allele (His allele).

A higher ratio of total meat to total fruit, berry and vegetable intake was positively associated with colorectal adenomas. For the high-risk adenomas this positive association was more obvious for the common allele (Tyr allele) of the EPHX1 codon 113 polymorphism. The same was seen for the EPHX1 codon 113 polymorphism in the low-risk adenomas, although not so obvious. The ratio $\left(\mathrm{Q}_{2}\right)$ was also associated with an increased risk of high-risk and low-risk adenomas in individuals with the GSTM1 common allele and the GSTP1 codon 105 variant allele (Val allele).

Statistical analysis of the modifying effect by the GSTT1 polymorphism on the ratio of total meat to total fruit, berries and vegetables intake was not possible to perform due to low sample size.

\section{Discussion}

Sporadic CRC is a consequence of multiple risk factors, among which the interaction between environmental and genetic factors is of particular interest. In this case-control study we investigated whether the consumption of meat and fruit, berries and vegetables or selected genotypes was associated with risk of developing colorectal carcinomas and adenomas alone or if the genotypes could modify the results.

We found only a weak positive association between total meat consumption and low-risk adenomas. Lack of significant association with the cancer group and the high-risk adenoma group, may be due to small sample size. There appears to be consistent evidence from epidemiological data that intake of red meat is positively related to risk of developing CRC [8,9]. Enhanced risk of colorectal adenomas, an established precursor lesion of CRC, has also been associated with high levels of red meat consumption in some studies $[36,37]$ but not in others $[38,39]$.

We did not detect any association between fruit, berry and vegetable intake and risk of developing colorectal carcinomas or adenomas. The association between fruit and vegetables consumption has not been consistently proven in other studies. The majority of case-control studies show an inverse association between intake of vegetables and colon cancer risk, while prospective studies show no association [40]. Distribution of meat, vegetable, fruit and berry consumption in our study is in agreement with the NORKOST survey, a nation-wide survey of a representative sample of the adult population in Norway [41].

The ratio between total meat and total fruit, berry and vegetable intake yielded an increased risk of high and lowrisk adenomas for the $2^{\text {nd }}$ quartile (and also the $3^{\text {rd }}$ quartile for low-risk adenomas) compared to the lower quartile. This result may apply to the general Norwegian population which has little variation in intake of meat, fruit, berries and vegetables. The result is in agreement with the result of Turner et al.[42] who showed that subjects who consumed small amounts of fruit and vegetables per month and many servings of red meat were at greater risk of CRC. The results also support the hypothesis of Kapiszewska [13] who has argued that it is not the consumption of a single food product or an individual component of diet, but rather a proper ratio of vegetables to meat consumption that contributes to cancer prevention. Lack of balance between the amount of meat and fruit, berries and vegetables may lead to the accumulation of damaged DNA, initiating DNA instability and inducing cancer development.

The GSTM1, GSTT1 and GSTP1 polymorphisms were not associated with risk of colorectal carcinomas and adeno- 
Table 4: Ratios of total meat to total fruit, berry and vegetable intake and the risk of colorectal carcinomas and adenomas by GST and EPHXI genotypes

\begin{tabular}{|c|c|c|c|c|c|c|c|c|c|}
\hline \multirow{3}{*}{ Case group } & \multirow{3}{*}{$\begin{array}{l}\text { Ratio of total meat to total } \\
\text { fruit, berry and vegetable } \\
\text { intake }\end{array}$} & \multicolumn{8}{|c|}{ OR $(95 \% \mathrm{Cl})^{\mathrm{a}}\left(\mathbf{N}_{\text {cases }} / \mathbf{N}_{\text {controls }}\right)$} \\
\hline & & \multicolumn{2}{|c|}{ GSTMI } & \multicolumn{2}{|c|}{ GSTPI Ile ${ }^{105} \mathrm{Val}$} & \multicolumn{2}{|c|}{ EPHXI Tyr ${ }^{1 / 3} \mathrm{His}$} & \multicolumn{2}{|c|}{ EPHXI His ${ }^{139} \mathrm{Arg}$} \\
\hline & & Present & Null & Ile/lle & Ile/Val+Val/Val & Tyr/Tyr & Tyr/His+His/His & His/His & His/Arg+Arg/Arg \\
\hline \multirow[t]{5}{*}{ Carcinomas } & $\mathbf{Q}_{1}$ & I (ref) $(11 / 39)$ & I (ref) $(I I / 36)$ & I (ref) $(7 / 32)$ & I (ref) $(15 / 43)$ & I (ref) $(10 / 33)$ & I (ref) $(10 / 42)$ & I (ref) $(9 / 5 I)$ & I (ref) $(I I / 24)$ \\
\hline & $\mathbf{Q}_{2}$ & $\begin{array}{c}0.84(0.20-3.47) \\
(11 / 33)\end{array}$ & $\begin{array}{c}2.99(0.85-10.5) \\
(18 / 40)\end{array}$ & $\begin{array}{c}2.01(0.53-7.67) \\
(16 / 27)\end{array}$ & $\begin{array}{c}1.52(0.43-5.35) \\
(13 / 46)\end{array}$ & $\begin{array}{c}3.28(0.63-17.0) \\
(17 / 29)\end{array}$ & $\begin{array}{c}1.65(0.5|-5.4|) \\
(12 / 44)\end{array}$ & $\begin{array}{c}4.67(1.21-18.0) \\
(17 / 48)\end{array}$ & $\begin{array}{c}0.69(0.17-2.89) \\
(12 / 25)\end{array}$ \\
\hline & $\mathbf{Q}_{3}$ & $\begin{array}{c}1.05(0.31-3.57) \\
(19 / 43)\end{array}$ & $\begin{array}{c}2.39(0.63-9.02) \\
(18 / 32)\end{array}$ & $\begin{array}{c}1.85(0.48-7.18) \\
(15 / 31)\end{array}$ & $\begin{array}{c}1.22(0.36-4.13) \\
(22 / 44)\end{array}$ & $\begin{array}{c}2.59(0.47-14.3) \\
(18 / 36)\end{array}$ & $\begin{array}{c}1.34(0.40-4.42) \\
(17 / 39)\end{array}$ & $\begin{array}{c}2.78(0.71-11.0) \\
(20 / 45)\end{array}$ & $\begin{array}{c}0.63(0.16-2.55) \\
(14 / 30)\end{array}$ \\
\hline & $\mathbf{Q}_{4}$ & $\begin{array}{c}0.49(0.10-2.41) \\
(12 / 33)\end{array}$ & $\begin{array}{c}0.78(0.19-3.23)(8 / \\
42)\end{array}$ & $\begin{array}{c}1.61(0.41-6.40) \\
(13 / 28)\end{array}$ & $\begin{array}{c}0.11(0.01-0.88)(7 / \\
47)\end{array}$ & $\begin{array}{c}0.70(0.11-4.59)(7 / \\
33)\end{array}$ & $\begin{array}{c}0.63(0.16-2.52) \\
(11 / 42)\end{array}$ & $\begin{array}{c}0.90(0.20-4.13) \\
(10 / 46)\end{array}$ & $\begin{array}{c}0.34(0.07-1.72)(8 / \\
29)\end{array}$ \\
\hline & & $P_{\text {trend }}=0.55$ & $P_{\text {trend }}=0.51$ & $P_{\text {trend }}=0.58$ & $P_{\text {trend }}=0.10$ & $P_{\text {trend }}=0.56$ & $P_{\text {trend }}=0.51$ & $P_{\text {trend }}=0.74$ & $P_{\text {trend }}=0.21$ \\
\hline \multirow{5}{*}{$\begin{array}{l}\text { High-risk } \\
\text { Adenomas }\end{array}$} & $\mathbf{Q}_{1}$ & I (ref) $(11 / 39)$ & I (ref) $(I 1 / 36)$ & I (ref) $(9 / 32)$ & I (ref) $(13 / 43)$ & I (ref) $(5 / 33)$ & I (ref) (17/42) & I (reff $(15 / 51)$ & I (ref) $(7 / 24)$ \\
\hline & $\mathbf{Q}_{2}$ & $\begin{array}{c}3.52(1.26-9.85) \\
(32 / 33)\end{array}$ & $\begin{array}{c}2.05(0.80-5.26) \\
(23 / 40)\end{array}$ & $\begin{array}{c}2.54(0.85-7.54) \\
(20 / 27)\end{array}$ & $\begin{array}{c}2.67(1.09-6.5 I) \\
(35 / 46)\end{array}$ & $\begin{array}{c}8.98(2.54-31.8) \\
(33 / 29)\end{array}$ & $\begin{array}{c}1.26(0.52-3.05) \\
(22 / 44)\end{array}$ & $\begin{array}{c}2.55(1.05-6.24) \\
(29 / 48)\end{array}$ & $\begin{array}{c}2.68(0.88-8.19) \\
(26 / 25)\end{array}$ \\
\hline & $\mathbf{Q}_{3}$ & $\begin{array}{c}1.49(0.53-4.21) \\
(22 / 43)\end{array}$ & $\begin{array}{c}1.57(0.59-4.20) \\
(23 / 32)\end{array}$ & $\begin{array}{c}1.32(0.42-4.16) \\
(12 / 31)\end{array}$ & $\begin{array}{c}1.42(0.57-3.56) \\
(33 / 44)\end{array}$ & 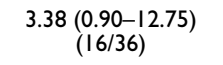 & $\begin{array}{c}1.08(0.45-2.63)(29 / \\
39)\end{array}$ & $\begin{array}{c}2.00(0.8 \mid-4.94) \\
(3 \mid / 45)\end{array}$ & $\begin{array}{c}0.93(0.28-3.10) \\
(14 / 30)\end{array}$ \\
\hline & $\mathbf{Q}_{4}$ & $\begin{array}{c}1.83(0.59-5.63) \\
(19 / 33)\end{array}$ & $\begin{array}{c}1.91(0.74-4.92) \\
(32 / 42)\end{array}$ & $\begin{array}{c}1.89(0.60-5.95) \\
(16 / 28)\end{array}$ & $\begin{array}{c}1.68(0.67-4.19) \\
(35 / 47)\end{array}$ & $\begin{array}{c}3.65(1.00-13.3) \\
(21 / 33)\end{array}$ & $\begin{array}{c}1.44(0.59-3.52) \\
(30 / 42)\end{array}$ & $\begin{array}{c}1.94(0.77-4.88) \\
(3 \mid / 46)\end{array}$ & $\begin{array}{c}1.65(0.52-5.26) \\
(20 / 29)\end{array}$ \\
\hline & & $P_{\text {trend }}=0.8 \mathrm{I}$ & $P_{\text {trend }}=0.34$ & $P_{\text {trend }}=0.59$ & $P_{\text {trend }}=0.74$ & $P_{\text {trend }}=0.67$ & $P_{\text {trend }}=0.5 \mathrm{I}$ & $P_{\text {trend }}=0.33$ & $P_{\text {trend }}=0.94$ \\
\hline \multirow[t]{5}{*}{$\begin{array}{l}\text { Low-risk } \\
\text { adenomas }\end{array}$} & $\mathbf{Q}_{1}$ & I (ref) $(36 / 39)$ & I (ref) $(54 / 36)$ & I (ref) $(44 / 32)$ & I (ref) $(46 / 43)$ & I (ref) $(38 / 33)$ & I (ref) $(52 / 42)$ & I (ref) $(57 / 5 \mid)$ & I (ref) (33/24) \\
\hline & $\mathbf{Q}_{2}$ & $\begin{array}{c}2.62(1.28-5.35) \\
(65 / 33)\end{array}$ & $\begin{array}{c}1.32(0.70-2.48) \\
(77 / 40)\end{array}$ & $\begin{array}{c}1.38(0.67-2.83) \\
(52 / 27)\end{array}$ & $\begin{array}{c}2.02(1.08-3.77) \\
(90 / 46)\end{array}$ & $\begin{array}{c}2.65(1.28-5.46) \\
(83 / 29)\end{array}$ & $\begin{array}{c}1.15(0.61-2.14) \\
(59 / 44)\end{array}$ & $\begin{array}{c}1.67(0.94-2.98) \\
(82 / 48)\end{array}$ & $\begin{array}{c}1.86(0.83-4.15) \\
(60 / 25)\end{array}$ \\
\hline & $\mathbf{Q}_{3}$ & $\begin{array}{c}1.89 \begin{array}{c}(0.96-3.74) \\
(81 / 43)\end{array}\end{array}$ & $\begin{array}{c}1.63(0.85-3.12) \\
(94 / 32)\end{array}$ & $\begin{array}{c}1.42(0.71-2.85) \\
(70 / 31)\end{array}$ & $\begin{array}{c}1.86(1.00-3.47) \\
(105 / 44)\end{array}$ & $\begin{array}{c}2.07(1.02-4.20) \\
(93 / 36)\end{array}$ & $\begin{array}{c}1.36(0.73-2.54) \\
(82 / 39)\end{array}$ & $\begin{array}{c}1.64(0.91-2.93) \\
(97 / 45)\end{array}$ & $\begin{array}{c}1.70(0.78-3.71) \\
(78 / 30)\end{array}$ \\
\hline & $\mathbf{Q}_{4}$ & $\begin{array}{c}1.89 \begin{array}{c}(0.90-3.98) \\
(80 / 33)\end{array}\end{array}$ & $\begin{array}{c}1.06(0.55-2.04) \\
(88 / 42)\end{array}$ & $\begin{array}{c}1.25(0.60-2.65) \\
(74 / 28)\end{array}$ & $\begin{array}{c}1.43(0.75-2.73) \\
(94 / 47)\end{array}$ & $\begin{array}{c}1.57(0.74-3.35) \\
(90 / 33)\end{array}$ & $\begin{array}{c}1.23(0.65-2.33) \\
(79 / 42)\end{array}$ & $\begin{array}{c}1.52(0.83-2.79) \\
(111 / 46)\end{array}$ & $\begin{array}{c}1.13(0.50-2.56) \\
(58 / 29)\end{array}$ \\
\hline & & $P_{\text {trend }}=0.25$ & $P_{\text {trend }}=0.80$ & $P_{\text {trend }}=0.55$ & $P_{\text {trend }}=0.48$ & $P_{\text {trend }}=0.49$ & $P_{\text {trend }}=0.46$ & $P_{\text {trend }}=0.22$ & $P_{\text {trend }}=0.98$ \\
\hline
\end{tabular}

OR adjusted for age, gender, smoking dose and alcohol consumption

Quartiles of ratio of total meat to total fruit, berry and vegetable intake, per day: $\leq 0.19,>0.19$ and $\leq 0.38,>0.38$ and $\leq 0.7 \mathrm{I},>0.7 \mathrm{I}$.

ref: The combination served as a reference. 
mas in this study. This is consistent with the results in some studies [33,43], but only partly in others [44].

The EPHX1 113His allele was associated with a decreased risk of low-risk adenomas. The EPHX1 codon 139 polymorphism was not associated with risk of carcinomas and adenomas in this study. Contradictory data have been provided by different studies investigating the EPHX1 codon 113 and EPHX 1 codon 139 polymorphisms in relation to the risk of colorectal carcinomas and adenomas [45-50].

There is conflicting evidence regarding the role of GST and EPHX1 polymorphisms in CRC susceptibility. Since the enzymes have detoxifying activity, it would be expected that, rather than affecting the risk of cancer per se, they would modify risk when exposed to potential carcinogens [22].

To evaluate if the genetic polymorphisms in GST and EPHX1 modify colorectal carcinoma and adenoma risk in relation to ratio of total meat to total fruit, berry and vegetable intake, we stratified the case groups based on the most common allele or any polymorphic allele.

The most convincing evidence of a modifying effect by genotype on dietary exposure was found between EPHX1 codon 113 in adenomas and EPHX1 codon 139 in carcinomas. In our study, for both the EPHX1 codon 113 and EPHX1 codon 139 polymorphisms, the increased risk associated with a higher ratio of total meat to total fruit, berries and vegetables was confined to individuals homozygous for the most common alleles (EPHX1 113Tyr allele and EPHX1 139His allele). To our knowledge no studies have been published on the association between GST and EPHX1 polymorphisms and the ratio of total meat to total fruit, berry and vegetable intake, but some studies have looked at the gene-diet interaction with meat and fruit/vegetables separately. There are few reports on the association between EPHX1 polymorphisms and dietary factors. Cortessis et al.[46] reported increased risk of adenomas in individuals who ate their meat well done and had a high predicted EPHX1 activity (combination with 3 or 4 of the more stable alleles, defined as the $\mathrm{Y}$ (tyrosine) variant at exon 3 and the $\mathrm{R}$ (arginine) variant at exon 4), whereas Ulrich et al.[51] reported elevated adenoma risks associated with low predicted activity in those with high intake of cooked meat. Other reports on EPHX1 and CRC and adenomas did not find evidence for an interaction with meat intake $[42,47,48,50]$. One report has suggested a weak interaction between fruit consumption and the EPHX1 113Tyr allele (common allele) [42], but due to unusual allele frequencies and unexpected pattern of results (greatest risk reduction in the intermediate genotype group) this finding must be interpreted with caution. The biochemical pathways in which EPHX1 participates involve numerous enzymes. The role of EPHX1 itself maybe quite complex, as the enzyme has broad substrate specificity and tissue distribution. Expression of EPHX1 is both induced and inhibited by exogenous compounds [52]. While EPHX1 usually results in detoxification of xenobiotic substances, it is also involved in the metabolic activation of polycyclic aromatic hydrocarbons found in cooked meat, triggering the formation of highly reactive metabolites that can damage DNA, RNA and protein components [35,53]. EPHX1 activity may also be modulated by components in fruit and vegetables. It is likely that EPHX1 could modify the association between diet and colorectal carcinoma and adenoma risk.

In addition we found weak evidence of a modifying effect by the GSTP1 and GSTM1 genotypes on the ratio of total meat to total fruit, berry and vegetable intake in adenomas. The increased risk associated with a higher ratio of total meat to total fruit, berries and vegetables is restricted to individuals with the GSTP1 codon 105 variant allele (Val allele), and to the GSTM1 common allele. Since there are no significant trends and only a few significant single results caution is required in interpretation of our findings.

Studies have shown that higher levels of DNA damage are associated with the GSTM1/T1 null genotypes and the GSTP1 105Val allele [54,55]. The higher adenoma risk with a low capacity GST variant could directly reflect the slower processing of genotoxic compounds associated with meat intake. In addition a high ratio of meat to fruit, berries and vegetables may increase the risk of carcinogenesis.

Isothiocyanates (component of fruit and vegetables) are substrates for GSTs [56-58] and thus GSTs contribute to the excretion of isothiocyanates. The involvement of GSTs in isothiocyanate metabolism has led to the hypothesis that, through slower excretion of isothiocyanates from the body in individuals with genetic variants associated with lower GST capacity, isothiocyanates have greater opportunity to exert their chemo-protective effects in these individuals [59].

As with any case-control study, there is a possibility of bias in recall of diet leading to spurious associations. But for the assessment of gene-environment interactions this is not an issue, since there is no corresponding risk of bias in relation to genotype. We cannot exclude the possibility that the associations may be confounded or modified by other genetic or dietary factors. The CRC cases and controls have not been matched by age, which may affect the results in our study. However, the controls were recruited from the same population as the adenoma and carcinoma 
cases. Further, our controls have been screened and found polyp free by flexible sigmoidoscopy and the risk of any of them having colon cancer at the time of inclusion is not very likely. It has been estimated that less than $3 \%$ of individuals with no adenoma at flexible sigmoidoscopy are likely to harbor an undiagnosed proximal advanced colorectal neoplasia [60].

Due to the high number of multiple tests and comparisons in the present study, some statistically significant associations have undoubtedly occurred by chance, and caution is required in their interpretation. The results thus need to be verified by further studies with particular focus on the ratio between meat and fruit, berry and vegetable intake and the possible modifying effects of biotransformation genes.

\section{Conclusion}

Although, the majority of the comparison groups are not significant, our results suggest an increased risk of colorectal adenomas in individuals for some of the higher ratio of total meat to total fruit, berry and vegetable intake. An unbalanced consumption of meat and fruit, berries and vegetables may lead to accumulation of DNA damage and thus increased risk of cancer development. In addition the study supports the notion that the biotransformation enzymes GSTM1, GSTP1 and EPHX1 may modify the effect of dietary factors on the risk of developing colorectal carcinoma and adenoma.

\section{Competing interests}

The author(s) declare that they have no competing interests.

\section{Authors' contributions}

CFS prepared the first draft of the paper. She prepared, with contribution from MS, the dietary data for statistical analysis. She did the data analysis and participated in genotyping of the samples. MS also contributed to the manuscript and with advice in the data analysis, and she participated in genotyping of the samples. AH advised on handling of the dietary data and statistical analysis. GH together with TG and KMT were responsible for designing and administering the NORCCAP clinical trial. In addition GH and TG provided advice on the statistical analysis. ILH participated in collection and quality control of the questionnaires. EHK initiated the KAM study and also organized it. She contributed with advice on data analysis and was responsible for the revisions of the manuscript. All authors discussed the results, contributed to interpretation of the results and the final manuscript.

\section{Acknowledgements}

This study was supported by the Norwegian Cancer Society (Grant numbers 51024/00I and EOI-085100I), Telemark University College (Grant number 22069), the Norwegian Colorectal Cancer Prevention (NORC-
CAP) study (Grants from the Norwegian Cancer Society and the Department of Health and Social Affairs), with the aid of EXTRA funds from the Norwegian Foundation for Health and Rehabilitation (200I/2/0I I0), Eastern Norway Regional Health Authority.

We thank Dr. Gunter Bock and Dr. Egil Johnson for collecting tumor tissues, Dr. Steinar Aase and Dr. Inger Marie B. Lothe for contributing to the pathology of the cancer cases and Thor Arne Haukedal, Thomas Bekkevold, Lene Løkås and Hege Storheil for technical assistance.

\section{References}

I. Cancer in Norway 2005. Cancer Registry of Norway, Institute of Population-based Cancer Research 2006.

2. Doll R, Peto R: The causes of cancer: quantitative estimates of avoidable risks of cancer in the United States today. J Natl Cancer Inst 1981, 66(6): 1 191-1308.

3. Thomas HJ: Familial colorectal cancer. Bmj 1993, 307(6899):277-278.

4. Armstrong B, Doll R: Environmental factors and cancer incidence and mortality in different countries, with special reference to dietary practices. Int J Cancer 1975, I 5(4):6 I7-63I.

5. Greenwald $P$, Clifford CK, Milner JA: Diet and cancer prevention. Eur J Cancer 200I, 37(8):948-965.

6. World Cancer Research Fund, Food, nutrition and the prevention of cancer: a global perspective. American Institute for Cancer Research, Washington DC; 1997.

7. Norat T, Riboli E: Meat consumption and colorectal cancer: a review of epidemiologic evidence. Nutr Rev 200I, 59(2):37-47.

8. Sandhu MS, White IR, McPherson K: Systematic review of the prospective cohort studies on meat consumption and colorectal cancer risk: a meta-analytical approach. Cancer Epidemiol Biomarkers Prev 200I, I 0(5):439-446.

9. Norat T, Lukanova A, Ferrari P, Riboli E: Meat consumption and colorectal cancer risk: dose-response meta-analysis of epidemiological studies. Int J Cancer 2002, 98(2):24I-256.

10. Giovannucci E: Diet, body weight, and colorectal cancer: a summary of the epidemiologic evidence. J Womens Health (Larchmt) 2003, I2(2): 173-182.

II. Hill MJ: Meat and colorectal cancer: what does the evidence show? Eur J Cancer Prev 1997, 6(5):415-417.

12. Hill MJ: Meat and cancer. Eur J Cancer Prev 1999, 8(3): 173- 174.

13. Kapiszewska M: A vegetable to meat consumption ratio as a relevant factor determining cancer preventive diet. The Mediterranean versus other European countries. Forum Nutr 2006, 59:130-153.

14. Caporaso N, Landi MT, Vineis P: Relevance of metabolic polymorphisms to human carcinogenesis: evaluation of epidemiologic evidence. Pharmacogenetics 1991, I(I):4-19.

15. Kiyohara C: Genetic polymorphism of enzymes involved in xenobiotic metabolism and the risk of colorectal cancer. J Epidemiol 2000, I0(5):349-360.

16. Hirvonen A: Polymorphisms of xenobiotic-metabolizing enzymes and susceptibility to cancer. Environ Health Perspect 1999, I07(Suppl I):37-47.

17. Hayes JD, Pulford DJ: The glutathione S-transferase supergene family: regulation of GST and the contribution of the isoenzymes to cancer chemoprotection and drug resistance. Crit Rev Biochem Mol Biol 1995, 30(6):445-600.

18. Zhou W, Liu G, Thurston SW, Xu LL, Miller DP, Wain JC, Lynch T], Su L, Christiani DC: Genetic polymorphisms in $\mathbf{N}$-acetyltransferase-2 and microsomal epoxide hydrolase, cumulative cigarette smoking, and lung cancer. Cancer Epidemiol Biomarkers Prev 2002, II(I): I5-2I.

19. Hassett C, Aicher L, Sidhu JS, Omiecinski C): Human microsomal epoxide hydrolase: genetic polymorphism and functional expression in vitro of amino acid variants. Hum Mol Genet 1994, 3(3):42I-428.

20. Pavanello $\mathrm{S}$, Clonfero $\mathrm{E}$ : Biological indicators of genotoxic risk and metabolic polymorphisms. Mutat Res 2000, 463(3):285-308.

21. Hayes JD, Flanagan JU, Jowsey IR: Glutathione transferases. Annu Rev Pharmacol Toxicol 2005, 45:5I-88. 
22. Cotton SC, Sharp L, Little J, Brockton N: Glutathione S-transferase polymorphisms and colorectal cancer: a HuGE review. Am J Epidemiol 2000, I 5 I (I):7-32

23. Johansson AS, Stenberg G, Widersten M, Mannervik B: Structureactivity relationships and thermal stability of human glutathione transferase $\mathrm{PI}-\mathrm{I}$ governed by the $\mathrm{H}$-site residue $\mathbf{I 0 5}$. J Mol Biol 1998, 278(3):687-698.

24. Gondal G, Grotmol T, Hofstad B, Bretthauer M, Eide TJ, Hoff G: The Norwegian Colorectal Cancer Prevention (NORCCAP) screening study: baseline findings and implementations for clinical work-up in age groups 50-64 years. Scand J Gastroenterol 2003, 38(6):635-642

25. ClinicalTrials.gov [http://www.clinicaltrials.gov]

26. Block G, Hartman AM, Dresser CM, Carroll MD, Gannon J, Gardner L: A data-based approach to diet questionnaire design and testing. Am J Epidemiol 1986, I 24(3):453-469.

27. Block G, Woods M, Potosky A, Clifford C: Validation of a selfadministered diet history questionnaire using multiple diet records. J Clin Epidemiol 1990, 43( I 2): I 327-I 335.

28. Block G, Thompson FE, Hartman AM, Larkin FA, Guire KE: Comparison of two dietary questionnaires validated against multiple dietary records collected during a I-year period. J Am Diet Assoc 1992, 92(6):686-693

29. Miller SA, Dykes DD, Polesky HF: A simple salting out procedure for extracting DNA from human nucleated cells. Nucleic Acids Res 1988, I 6(3): 1215

30. Hansen R, Saebo M, Skjelbred CF, Nexo BA, Hagen PC, Bock G, Bowitz Lothe IM, Johnson E, Aase S, Hansteen IL, Vogel U, Kure EH: GPX Pro I 98Leu and OGGI Ser326Cys polymorphisms and risk of development of colorectal adenomas and colorectal cancer. Cancer Lett 2005, 229(I):85-9I.

31. Nedelcheva Kristensen V, Andersen TI, Erikstein B, Geitvik G, Skovlund E, Nesland JM, Borresen-Dale AL: Single tube multiplex polymerase chain reaction genotype analysis of GSTMI, GSTTI and GSTPI: relation of genotypes to TP53 tumor status and clinicopathological variables in breast cancer patients. Pharmacogenetics 1998, 8(5):44I-447.

32. Garte S, Gaspari L, Alexandrie AK, Ambrosone C, Autrup H, Autrup LL, Baranova H, Bathum L, Benhamou S, Boffetta P, Bouchardy C, Breskvar K, Brockmoller J, Cascorbi I, Clapper ML, Coutelle C, Daly A, Dell'Omo M, Dolzan V, Dresler CM, Fryer A, Haugen A, Hein DW, Hildesheim A, Hirvonen A, Hsieh LL, Ingelman-Sundberg M, Kalina I, Kang D, Kihara M, Kiyohara C, Kremers P, Lazarus P, Le Marchand L, Lechner MC, van Lieshout EM, London S, Manni J], Maugard CM, Morita S, Nazar-Stewart V, Noda K, Oda Y, Parl FF, Pastorelli R, Persson I, Peters WH, Rannug A, Rebbeck T, Risch A, Roelandt L, Romkes M, Ryberg D, Salagovic J, Schoket B, Seidegard J, Shields PG, Sim E, Sinnet D, Strange RC, Stucker I, Sugimura H, To-Figueras J, Vineis P, Yu MC, Taioli E: Metabolic gene polymorphism frequencies in control populations. Cancer Epidemiol Biomarkers Prev 200I I 0( I 2): I 239-| 248.

33. Welfare M, Monesola Adeokun A, Bassendine MF, Daly AK: Polymorphisms in GSTPI, GSTMI, and GSTTI and susceptibility to colorectal cancer. Cancer Epidemiol Biomarkers Prev 1999, 8(4 Pt I):289-292.

34. De Roos AJ, Rothman N, Inskip PD, Linet MS, Shapiro WR, Selker RG, Fine HA, Black PM, Pittman GS, Bell DA: Genetic polymorphisms in GSTMI, -PI, -TI, and CYP2EI and the risk of adult brain tumors. Cancer Epidemiol Biomarkers Prev 2003, I 2(I): |4-22.

35. Smith CA, Harrison DJ: Association between polymorphism in gene for microsomal epoxide hydrolase and susceptibility to emphysema. Lancet 1997, 350(9078):630-633.

36. Sandler RS, Lyles CM, Peipins LA, McAuliffe CA, Woosley JT, Kupper LL: Diet and risk of colorectal adenomas: macronutrients, cholesterol, and fiber. J Natl Cancer Inst I993, 85( I I ):884-89I.

37. Neugut AI, Garbowski GC, Lee WC, Murray T, Nieves JW, Forde KA, Treat MR, Waye JD, Fenoglio-Preiser C: Dietary risk factors for the incidence and recurrence of colorectal adenomatous polyps. A case-control study. Ann Intern Med I 993, I I 8(2):91-95.

38. Giovannucci E, Stampfer MJ, Colditz G, Rimm EB, Willett WC: Relationship of diet to risk of colorectal adenoma in men. J Natl Cancer Inst 1992, 84(2):91-98.

39. Tiemersma EW, Voskuil DW, Bunschoten A, Hogendoorn EA, Witteman BJ, Nagengast FM, Glatt H, Kok FJ, Kampman E: Risk of colorectal adenomas in relation to meat consumption, meat preparation, and genetic susceptibility in a Dutch population. Cancer Causes Control 2004, I 5(3):225-236.

40. Giovannucci E: Modifiable risk factors for colon cancer. Gastroenterol Clin North Am 2002, 3 I (4):925-943.

4I. Johansson L, Solvoll K, Bjørneboe GE, Drevon CA: Dietary habits among Norwegian men and women. Scandinavian Journal of Nutrition 1997, 41:63-70.

42. Turner F, Smith G, Sachse C, Lightfoot T, Garner RC, Wolf CR, Forman D, Bishop DT, Barrett JH: Vegetable, fruit and meat consumption and potential risk modifying genes in relation to colorectal cancer. Int J Cancer 2004, I I 2(2):259-264.

43. De Jong MM, Nolte IM, Te Meerman GJ, Van Der Graaf WT, De Vries EG, Sijmons RH, Hofstra RM, Kleibeuker JH: Low-penetrance Genes and Their Involvement in Colorectal Cancer Susceptibility. Cancer Epidemiol Biomarkers Prev 2002, I I (I I): I 332-I 352

44. Yeh CC, Hsieh LL, Tang R, Chang-Chieh CR, Sung FC: Vegetable/ fruit, smoking, glutathione S-transferase polymorphisms and risk for colorectal cancer in Taiwan. World J Gastroenterol 2005, I I ( I 0): | 473-| 480.

45. Sachse C, Smith G, Wilkie MJ, Barrett JH, Waxman R, Sullivan F, Forman D, Bishop DT, Wolf CR: A pharmacogenetic study to investigate the role of dietary carcinogens in the etiology of colorectal cancer. Carcinogenesis 2002, 23( I I): I839- I849.

46. Cortessis V, Siegmund K, Chen Q, Zhou N, Diep A, Frankl H, Lee E, Zhu QS, Haile R, Levy D: A case-control study of microsomal epoxide hydrolase, smoking, meat consumption, glutathione S-transferase M3, and risk of colorectal adenomas. Cancer Res 200I, 6 I (6):238I-2385.

47. Tranah G], Giovannucci E, Ma J, Fuchs C, Hankinson SE, Hunter DJ: Epoxide hydrolase polymorphisms, cigarette smoking and risk of colorectal adenoma in the Nurses' Health Study and the Health Professionals Follow-up Study. Carcinogenesis 2004 25(7): $|2||-12| 8$

48. Huang WY, Chatterjee N, Chanock S, Dean M, Yeager M, Schoen RE Hou LF, Berndt SI, Yadavalli S, Johnson CC, Hayes RB: Microsomal epoxide hydrolase polymorphisms and risk for advanced colorectal adenoma. Cancer Epidemiol Biomarkers Prev 2005 I4(I): I52-157.

49. Harrison DJ, Hubbard AL, MacMillan J, Wyllie AH, Smith CA: Microsomal epoxide hydrolase gene polymorphism and susceptibility to colon cancer. Br J Cancer 1999, 79(I): I68-I7I.

50. Robien K, Curtin K, Ulrich CM, Bigler J, Samowitz W, Caan B, Potter JD, Slattery ML: Microsomal epoxide hydrolase polymorphisms are not associated with colon cancer risk. Cancer Epidemiol Biomarkers Prev 2005, I4(5): I 350-I352.

5I. Ulrich CM, Bigler J, Whitton JA, Bostick R, Fosdick L, Potter JD: Epoxide hydrolase Tyrl 3 His polymorphism is associated with elevated risk of colorectal polyps in the presence of smoking and high meat intake. Cancer Epidemiol Biomarkers Prev 200 I, I 0(8):875-882

52. Seidegard J, DePierre JW: Microsomal epoxide hydrolase. Properties, regulation and function. Biochim Biophys Acta 1983, 695(3-4):25।-270.

53. Brown B, Avalos J, Lee C, Doolittle D: The effect of tobacco smoke, nicotine, and cotinine on the mutagenicity of 4(methylnitrosamino)-I-(3-pyridyl)- I-butanol (NNAL). Mutat Res 200I, 494(I-2):2I-29.

54. Norppa H: Genetic polymorphisms and chromosome damage. Int J Hyg Environ Health 200I, 204(I):3I-38.

55. Gilliland FD, Harms HJ, Crowell RE, Li YF, Willink R, Belinsky SA: Glutathione S-transferase PI and NADPH quinone oxidoreductase polymorphisms are associated with aberrant promoter methylation of P I 6(INK4a) and O(6)-methylguanineDNA methyltransferase in sputum. Cancer Res 2002 , 62(8):2248-2252.

56. Kolm RH, Danielson UH, Zhang Y, Talalay P, Mannervik B: Isothiocyanates as substrates for human glutathione transferases: structure-activity studies. Biochem J I 995, 3 I I (Pt 2):453-459.

57. Meyer DJ, Crease DJ, Ketterer B: Forward and reverse catalysis and product sequestration by human glutathione S-transferases in the reaction of GSH with dietary aralkyl isothiocyanates. Biochem J 1995, 306(Pt 2):565-569.

58. Zhang $Y$, Kolm RH, Mannervik B, Talalay P: Reversible conjugation of isothiocyanates with glutathione catalyzed by human glutathione transferases. Biochem Biophys Res Commun 1995 206(2):748-755. 
59. Lin HJ, Probst-Hensch NM, Louie AD, Kau IH, Witte JS, Ingles SA, Frankl HD, Lee ER, Haile RW: Glutathione transferase null genotype, broccoli, and lower prevalence of colorectal adenomas. Cancer Epidemiol Biomarkers Prev 1998, 7(8):647-652.

60. Gondal G, Grotmol T, Hofstad B, Bretthauer M, Eide TJ, Hoff G: Lifestyle-related risk factors and chemoprevention for colorectal neoplasia: experience from the large-scale NORCCAP screening trial. Eur J Cancer Prev 2005, I 4(4):373-379.

\section{Pre-publication history}

The pre-publication history for this paper can be accessed here:

http://www.biomedcentral.com/1471-2407/7/228/pre pub

Publish with Bio Med Central and every scientist can read your work free of charge

"BioMed Central will be the most significant development for disseminating the results of biomedical research in our lifetime. "

Sir Paul Nurse, Cancer Research UK

Your research papers will be:

- available free of charge to the entire biomedical community

- peer reviewed and published immediately upon acceptance

- cited in PubMed and archived on PubMed Central

- yours - you keep the copyright

Submit your manuscript here:

http://www.biomedcentral.com/info/publishing_adv.asp
BioMedcentral 